\title{
Research on Mutual Influence between Pipes of Curved Pipe-jacking Roof Project
}

\author{
Li Jian ${ }^{1,2}$ \\ ${ }^{1}$ Chang'an University, \\ Xi'an, China \\ ${ }^{2}$ Guangdong Nanyue Transportation Investment \& \\ Construction Co., Ltd., \\ Guangzhou, China \\ e-mail: lijian0757@126.com
}

\author{
Li Zhihong \\ Guangdong Nanyue Transportation Investment \& \\ Construction Co., Ltd. \\ Guangzhou, China \\ e-mail: lizhihong0701@163.com
}

\begin{abstract}
Considering the requirements of water sealing between pipes and control precision, the pipe roof currently implemented are all straight. Due to some special construction conditions, the pipe roof method needs to break the limit of linear condition. This results in several problems such as increasing the difficulty of precision control, enhancing the mutual influence between pipes, increasing the difficulty of forming roof and other issues. This study is based on the curved pipe-jacking roof project of Gongbei Tunnel of Zhuhai Link Road of Hong Kong-Zhuhai-Macao Bridge. Through the model test, numerical simulation and field test, the mutual influence between pipes of curved pipejacking roof is researched, and the laws of cumulative disturbance and strain of soil, pipe-soil contact pressure, influence of trajectory are analysed. The results demonstate that maximum soil cumulative is close to secondly jacked pipe and maximum pipe-soil contact pressure is loacted at horizontal position of firstly jacked pipe. The research provides reference for the construction of curved pipejacking project.
\end{abstract}

Keywords-curved; pipe-jacking; pipe roof; soil box experiment; mutual influence

\section{INTRODUCTION}

Pipe-roof method has increasingly application on tunnels and underground engineering because of its advantage such as low noise, on need of lowering ground water or wide range of excavation, few of effects on communal facilities and easy control of subsidence or other impact on the environment.

The first record on the application of pipe roof is the traversing channel project of Kawase-Inae in Japan, in 1971[1]. The souterrain construction in HK in 1984 is the earliest usage of this method in China. In 1989, pipe roof method is used with ESA culvert box advancing scheme on souterrain of Taipei Songshan Airport[2]. The same method is applied and achieved a few of scientific payoffs on the tunnel of Shanghai Middle Ring Line with 80 pipes which are $970 \mathrm{~mm}$ diameter[3-6]. Relevant scholars conducted research on ground deformation caused by pipes construction with the method of pipe jacking[7-10].

At present, the complete pipe roof projects are almost with straight pipes, grouting through locking wellhead because of lack of ground water. However, some pipe roof projects, such as the underground part of Gongbei Tunnel of Zhuhai Link Road on HK-Zhuhai-Macao Bridge, which is built by $255 \mathrm{~m}$ curved pipe roof and sealed by freezing method, need to be constructed by curve. This way increases the risks of sealing failure, track deflection and interaction of pipes. Based on this pipe roof project, this article analyze the interaction of pipes, which provides reference on this method.

\section{CURVED PIPE JACKING ROOF OF GONGBEI TUNNEL}

Gongbei Tunnel is the key project of Zhuhai Link Road of HK-Zhuhai-Macao Bridge. The tunnel is $2741 \mathrm{~m}$, which is constructed by the order of "parallel-overlapparallel". When pass under the Gongbei Port, excavation is coordinated with $255 \mathrm{~m}$ curved pipe roof $(88 \mathrm{~m}$ easement and $167 \mathrm{~m}$ circle) and freezing method. It is the first double-deck highway tunnel constructed by this method.

The excavation part of Gongbei Tunnel is $336 \mathrm{~m}^{2}$ oval cross section with double-deck overlap. Soil between 36 pipes, which is $1620 \mathrm{~mm}$ dia. and constructed by pipe jacking, is frozen to make strong-support waterproof curtain to maintain excavation face (as Fig .1). There is $0.35 \%$ grade on track from east to west, which encouters several soil layers, including filling soil, muddy-silty clay, silty soil, medium sand, mucky silt, silty clay, and gravelly sand. The characteristics of soil layers include: weak, waterlogged, rich water supplying, high compressibility, high permeability and low capacity. The thickness of covering soil is $4 \sim 5 \mathrm{~m}$. The pipe section is $4 \mathrm{~m}$ long, $20 \mathrm{~mm}$ of thickness on upper part of pipe-roof and $24 \mathrm{~mm}$ of thickness on lower half. A test pipe is designed to testing jacking precision, track control, interaction of pipes and some experience parameters. 


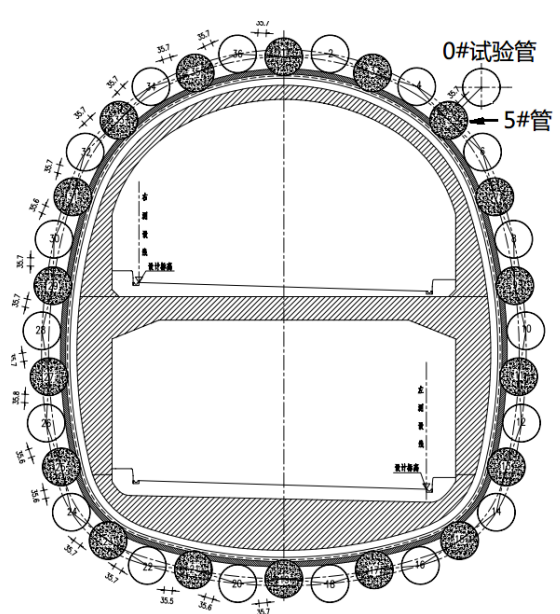

(a)

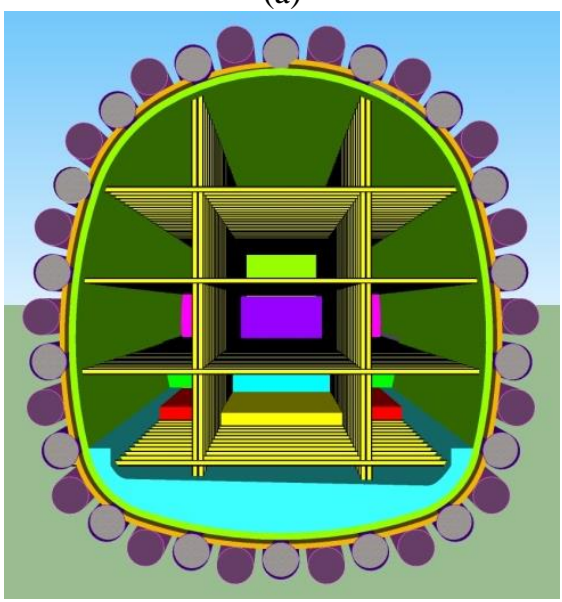

(b)

Figure 1. Schematic diagram of curved pipe-jacking roof project in Gongbei Tunnel

\section{SOIL BOX MODEL TEST AND RESULT ANALYSIS}

\section{Soil Box Model Test}

To study the mutual influence between pipe jacking, we carry out a soil box model test according to the similarity theory. As the Fig .2 shows, the test chamber wall is $3000 \mathrm{~mm}$ long, $1800 \mathrm{~mm}$ wide, $1500 \mathrm{~mm}$ high. The diameter of steel pipes is $324 \mathrm{~mm}$, wall thickness is $4 \mathrm{~mm}$, and length of the pips is $1500 \mathrm{~mm}$. The distance between the two pipes is $72 \mathrm{~mm}$. The combination of cutter and screw drill pipe device is as test simulation jacking device. The diameter of the cutter is $335 \mathrm{~mm}$. Test soil is $1500 \mathrm{~mm}$ of sand layer. Test data including posterior pipe jacking acts additional stress on the prior pipe jacking, ground surface deformation and the internal strain of soil, etc. 5 soil pressure sensors are set on the prior pipe jacking close to the posterior pipe jacking side respectively at $0^{\circ}, \pm 45^{\circ}$ and $\pm 90^{\circ}$ positions, as Fig .3 shows.

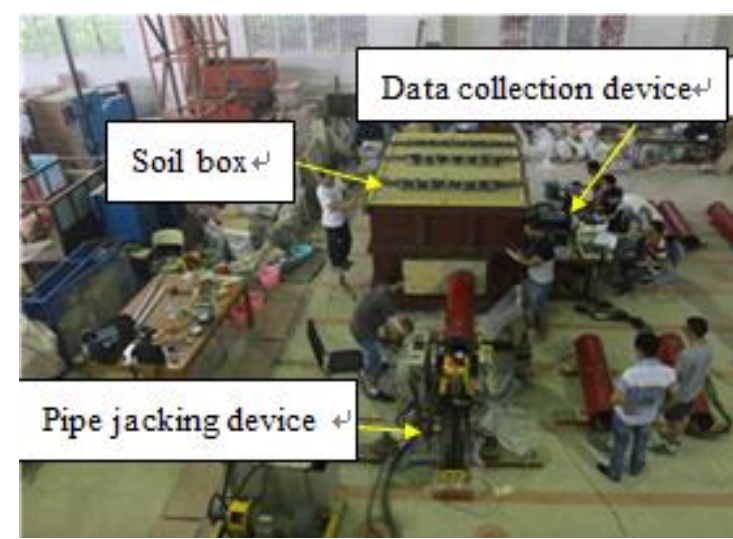

Figure 2. The soil box model test

This soil box test sets three ground settlement monitoring sections. In the process of group of pipe jacking, in order to monitor changes of strain of soil around the pipe jacking, respectively from the up and down the $225 \mathrm{~mm}$ pipe jacking axis laid fiber optic strain monitoring, as shown in Fig .4.

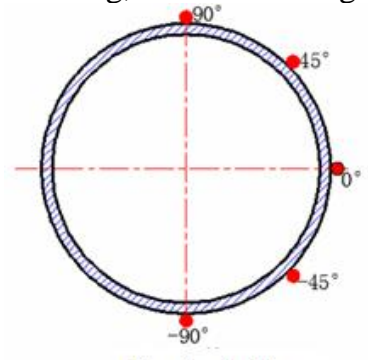

Prior pipe jacking

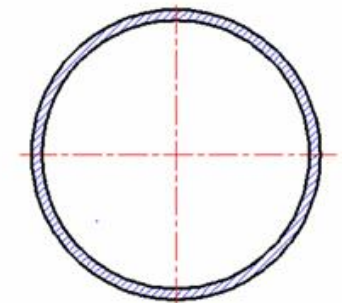

Posterior pipe jacking
Figure 3. Monitoring points of soil pressure

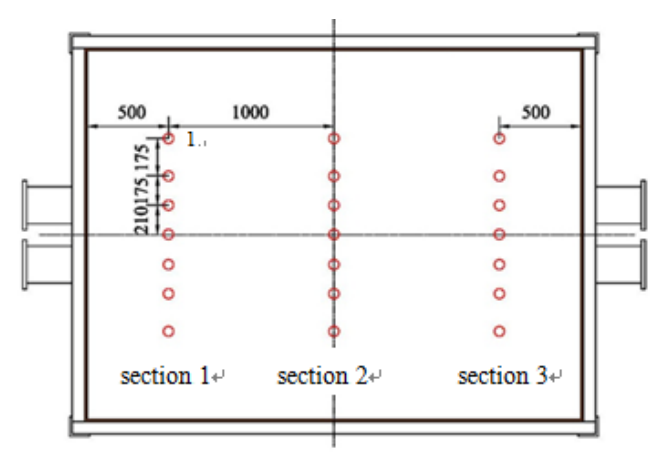

Figure 4(a). Ground settlement monitoring section

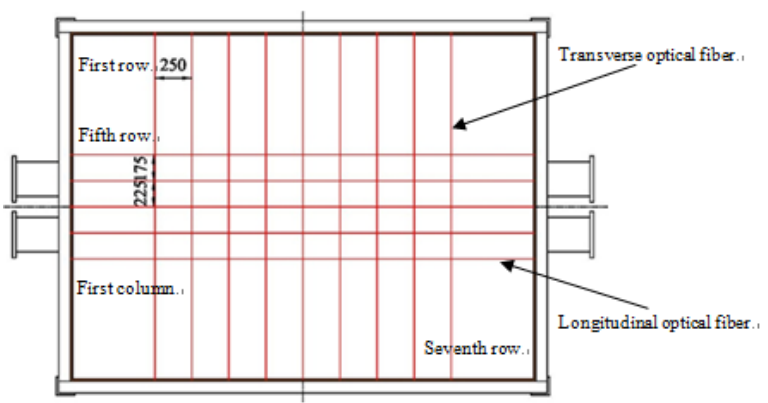

Figure 4(b). Strain monitoring 


\section{Analysis of test result}

Fig .5(a) is the deformation of settlement monitoring section 1 when the prior pipe jacked forward $10 \mathrm{~cm}$ and $50 \mathrm{~cm}$. The figure shows that soil uplift occurred in front of the pipe jacking machine, which is due to the additional thrust acted on the jacking machine cutter front. The maximum uplift above the top tube axis is $0.14 \mathrm{~mm}$ when jacking forward $10 \mathrm{~cm}$. When jacking forward $50 \mathrm{~cm}$, section 1 settlement occurred and the maximum settlement is $0.74 \mathrm{~mm}$. Fig .5(b) is the deformation of settlement monitoring section 1 when the posterior pipe jacked forward $10 \mathrm{~cm}$ and $50 \mathrm{~cm}$. After the completion of prior pipe jacking, monitoring section 1 were in an overall settling state. With the jacking of the posterior pipe, the settling tank developed continuously from $0.88 \mathrm{~mm}$ to $2.34 \mathrm{~mm}$. Surface subsidence demonstrated the cumulative effects and the maximum settlement position moved to near the top of the tube axis of the posterior pipe.

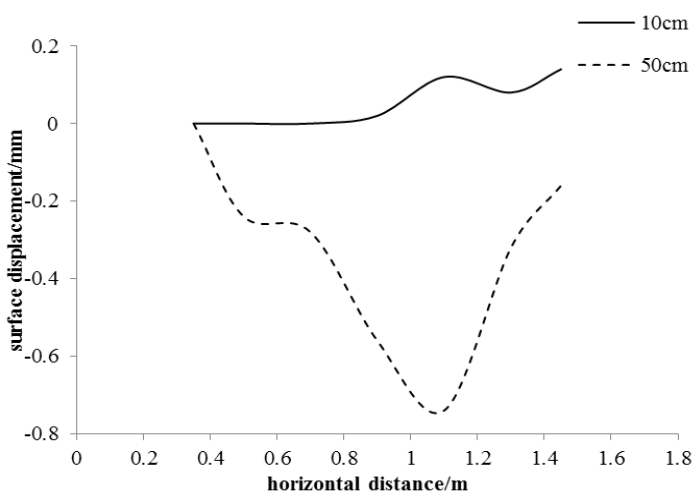

Figure 5(a). Settlement curve of monitoring section 1 when jacking at $10 \mathrm{~cm}$ and $50 \mathrm{~cm}$ for prior pipe

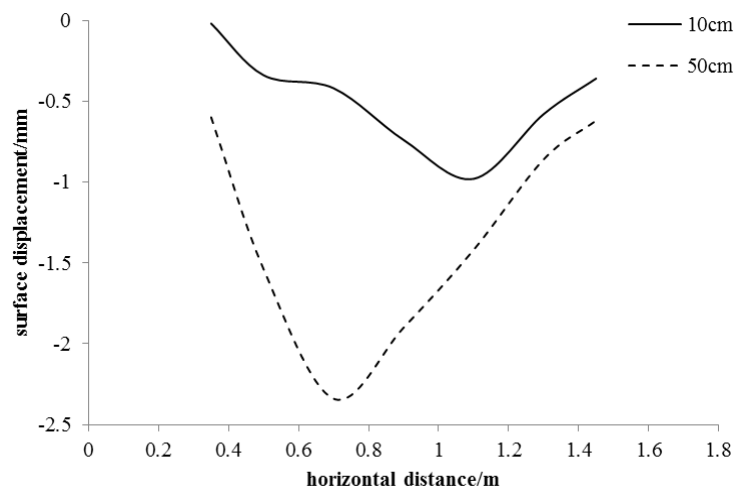

Figure 5(b). Settlement curve of monitoring section 1 when jacking at $10 \mathrm{~cm}$ and $50 \mathrm{~cm}$ of for posterior pipe

According to the results of the monitoring, the soil strain changes are more obvious in front of the pipe jacking machine. When First pipe jacked $60 \mathrm{~cm}$, the lateral optical fibers of strain changes mainly are concentrated in the front three rows, shown in Fig .6 (a). The strain of first row fiber optic increases near the front of jacked pipe axis, but decreases at both sides of the pipe jacking axis, which is due to the both sides extrusion effect of front soil by pipe jacking machine cutter. So the soil near the pipe axis makes the optical fiber emerging tensile strain. But the soil on both sides is under compression and the originally tensile strain existing in fiber decreases. The strain changes of second row fiber optic are also the same law with less strain changes. The strain of third row fiber optic is between $-500 \mu \varepsilon$ to $-600 \mu \varepsilon$, without concentration phenomenon. The strain influence on the longitudinal optical fibers is mainly concentrated from first column to fourth column, as shown in Fig .6 (b). It is shown that the longitudinal optical fiber strain upper prior pipe decreases, which is due to the surrounding soil compression under effect of positive additional thrust of pipe jacking machine cutter and the side friction, making previously optical fiber strain decrease. In the soil away from cutter, the strain affected by pipe jacking is smaller.

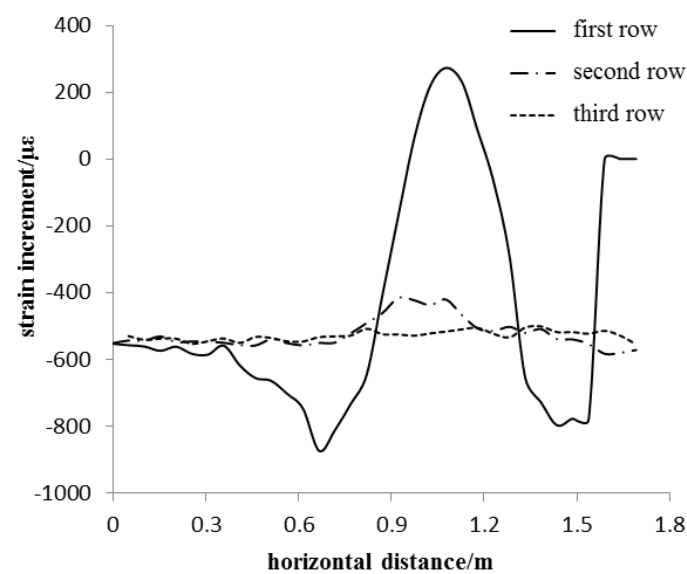

Figure 6(a). Strain increment of transverse fiber when the prior pipe jacked at $60 \mathrm{~cm}$

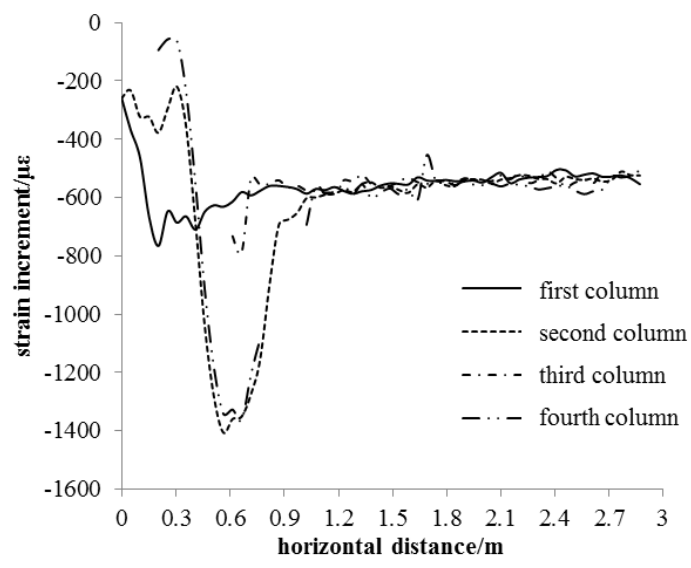

Figure 6(b). Strain increment of longitudinal fiber when the prior pipe jacked at $60 \mathrm{~cm}$

\section{NUMERICAL SIMULATION OF SOIL BOX MODEL TEST}

\section{A. Result and Analysis of Numerical Simulation}

In order to compare with the box model test, a numerical simulation model of soil box test is performed The calculation of soil parameters include elastic modulus (30 MPa), poisson's ratio $(0.3)$, density $\left(1650 \mathrm{~kg} / \mathrm{m}^{3}\right)$, internal friction angle $\left(35^{\circ}\right)$ and cohesion $(1 \mathrm{kPa})$. The calculated parameters of pipe are elastic modulus (210 $\mathrm{GPa})$, poisson's ratio $(0.3)$ and density $\left(7800 \mathrm{~kg} / \mathrm{m}^{3}\right)$ after 0.3 . In the numerical simulation model, the soil is using Mohr-coulomb model and pipe is using elastic model. For the boundary conditions, all direction displacements of 
bottom are constraint, but normal direction displacement of surrounding constraint and free on the surface. Before pipe jacking construction, the initial form of interaction between pipe and soil is set up. The pipe jacking construction process is simulated by displacement dynamic injection method with 8 excavation step, each step in jacking construction of $0.2 \mathrm{~m}$ (as shown in Fig .7). The total units are 85320 .

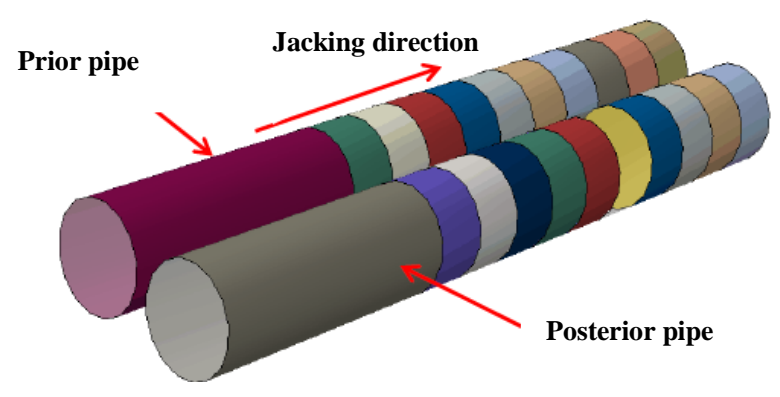

Figure 7. Excavating model

According to the calculation results, the maximum soil subsidence upper first pipe is up to $2.196 \mathrm{~mm}$ and the subsidence curve is deviation to first pipe. The soil subsidence increases during second pipe jacked, which reflects the cumulative effect of soil disturbance. The largest settlement reaches $2.659 \mathrm{~mm}$. The soil displacement curve is approximately symmetrical with center of soil box, after the completion of two pipe jacked, as shown in Fig .8.

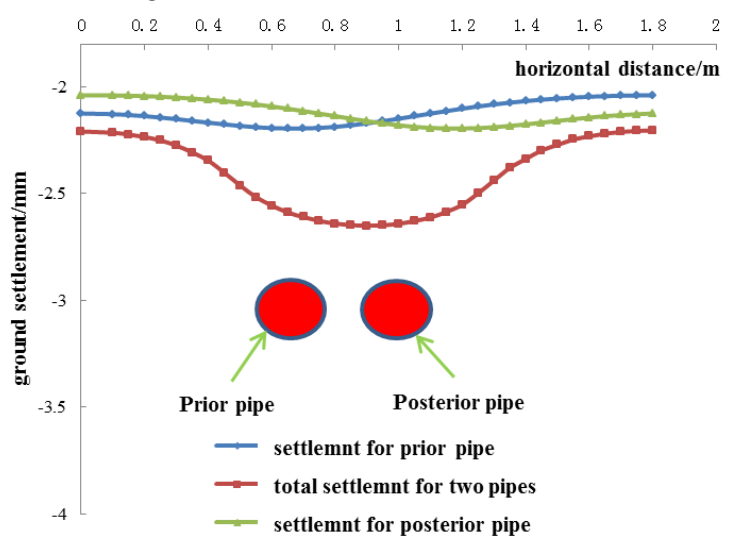

Figure 8. Settling tank when the posterior pipe jacked

Change of the contact pressure between prior jacking pipe and soil before and after the construction of posterior jacking pipe is shown in Fig .9(a) and Fig .9(b). The figures show that after the completion of prior pipe jacking, distribution of the contact pressure between pipe and soil is relatively uniform as about $4 \mathrm{kPa}$ and that after the completion of posterior pipe jacking, the contact pressure near the side of posterior pipe increases and the maximum pressure is about $6.35 \mathrm{kPa}$.

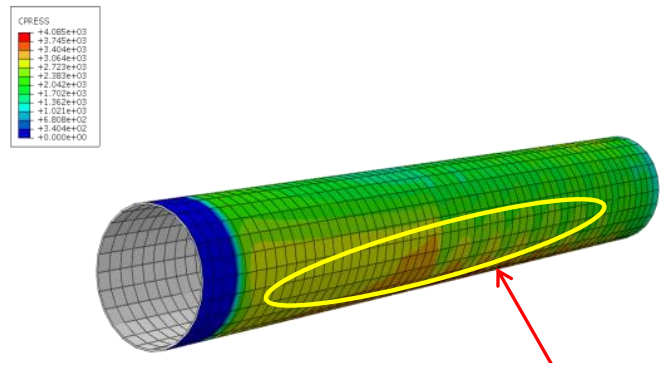

Figure 9(a). Contact pressure of the prior pipe before the posterior pipe jacked

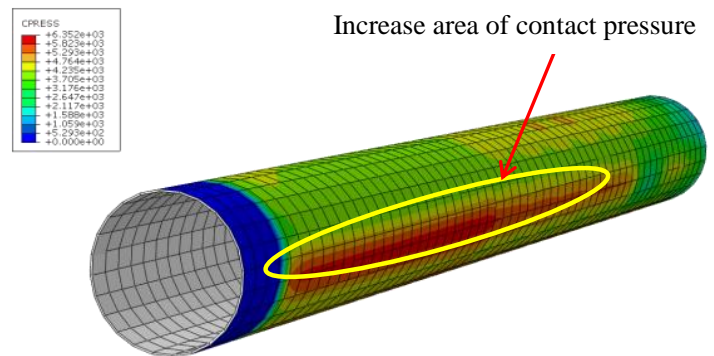

Figure 9(b). Contact pressure of the prior pipe after the posterior pipe jacked

\section{B. Comparison with the result of soil box test}

The subsidence comparison of numerical simulation results and model test on monitoring section one is as shown in Fig .10. It shows that both surface deformation curve trends are relatively close especially the maximum subsidence is close, while the results of soil-bin test are slightly larger than that of numerical simulation and compared with numerical simulation results the maximum settlement location of model test is closer to the pipe axis of posterior pipe, which is coincide with actual construction monitoring results. Besides, it is obtained that in a location near the walls on both sides there is comparatively large difference between each surface deformation with that the surface deformation of numerical simulation is obviously larger than that of soil-bin test. This is because that during the test process the friction force between soil and the walls limit the soil subsidence on both sides of walls to a certain extent, thus the numerical simulation result has more reference value.

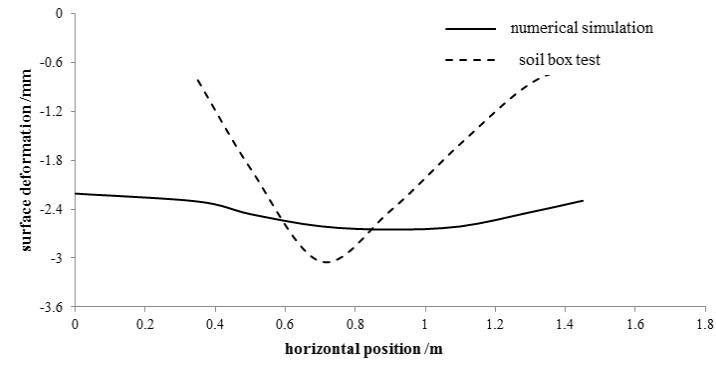

Figure 10. The contrast curve of simulation and model tests at No.1 settlement monitoring section

Fig .11(a) and Fig .11(b) show the law of later horizontal optical fiber strain in row 1 and 2 during jacking of prior pipe. It is obtained that the strain increment measured by optical fiber in soil-bin test is basically the 
same as that of numerical simulation, especially strain concentration occurred in soil that are right ahead of the prior pipe. The numerical difference of the two kinds strain is likely to be caused by the lack of coupling effect between soil and fiber.

The contrast curve of the prior pipe additional stress is shown in Fig .12, and additional stress curves of numerical simulation and soil-bin test have similarity. The additional soil pressure of prior pipe during the jacking process of posterior pipe at the horizontal position ( 0 degree) is the largest. However, the minimum additional soil pressure of soil-bin test occurs at the top and bottom of pipe while the minimum additional soil pressure of numerical simulation occurs where are plus-minus 45 degree of the pipe, and additional pressure of the bottom of pipe is less than that of the top of pipe. Due to the effect of pipe bearing load, soil in the bottom is less affected by disturbance, thus additional soil pressure is smaller accordingly.

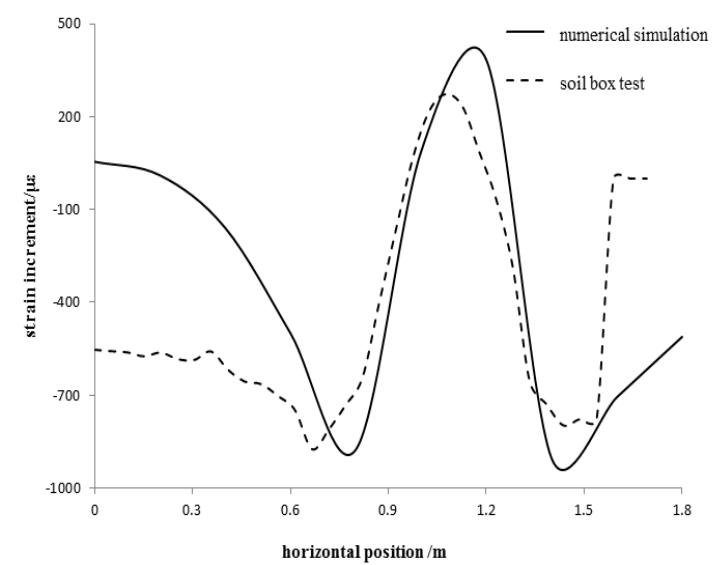

Figure 11(a). The contrast curve of strain increment of transverse fiber when the first pipe jacked at $40 \mathrm{~cm}$ in row 1

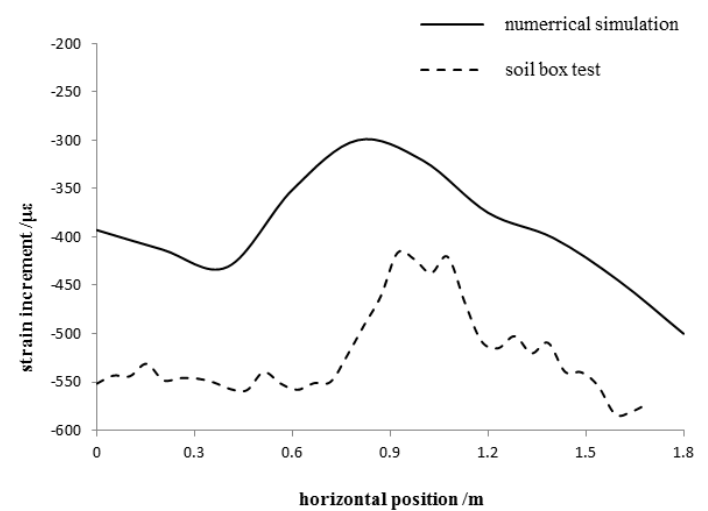

Figure 11 (b). The contrast curve of strain increment of transverse fiber when the first pipe jacked at $40 \mathrm{~cm}$ in row 2

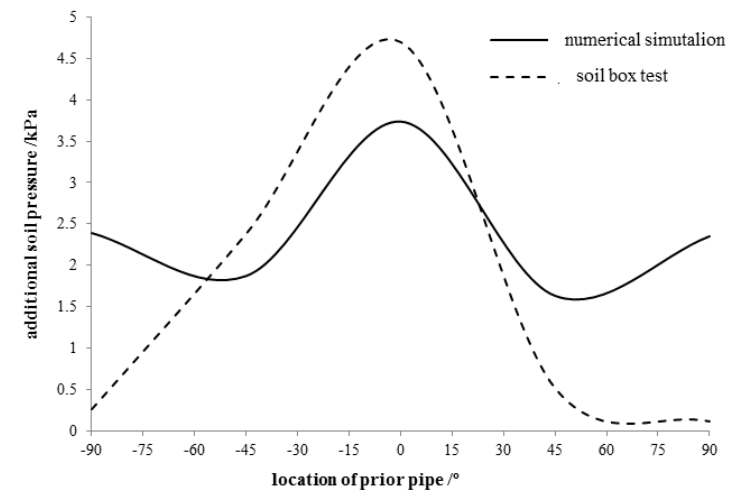

Figure 12. The contrast curve of superimposed soil pressure

\section{V.FIELD TEST}

The field tests were carried out in Gongbei tunnel construction site to have a further study on the interaction of pipes of the pipe-jacking roof, the 0\# test pipe and 5\# pipe are as shown in Fig .1. The test pipe is 255 meters long and about 7 8 meters deep. It is in the transition curve and circle curve, the curvature radius of which is $885.852 \mathrm{~m} \sim 906.298 \mathrm{~m}$. The pipe's diameter is $1620 \mathrm{~mm}$, and the thickness is $20 \mathrm{~mm}$, each pipe is 4 meters long, the spacing of the two test pipe is $35.7 \mathrm{~cm}$. The test pipe 0\# was jacking first, and then jacked pipe 5\#. The 0\# pipe's trajectory was measured and reviewed, as shown in Fig .13, while it was finished.
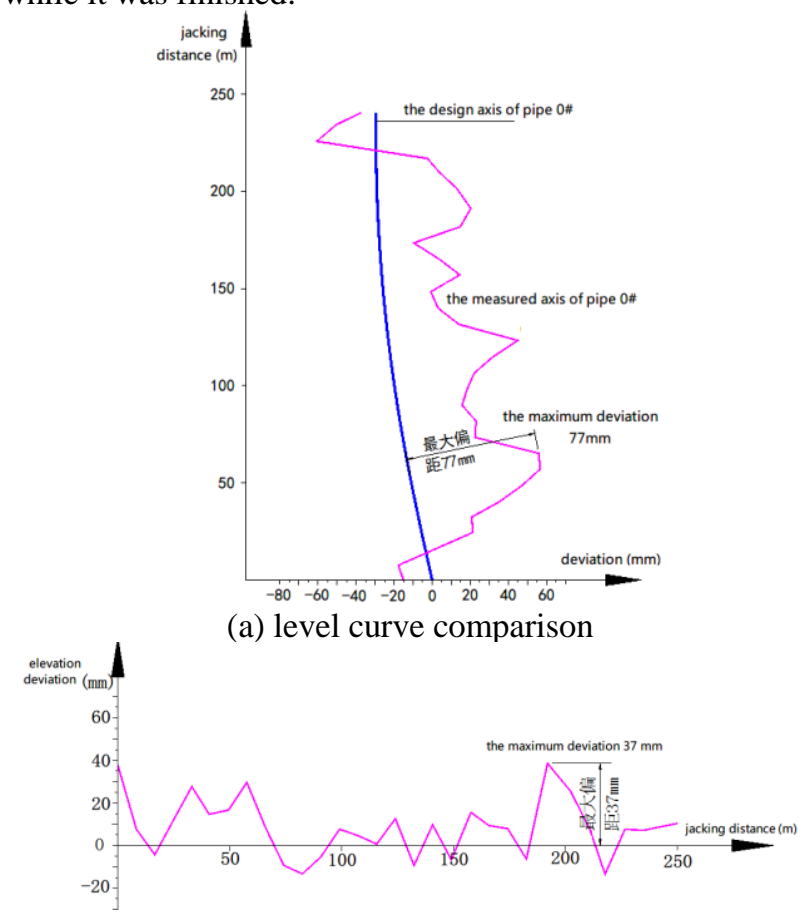

(b) height curve comparison

Figure 13. The curve of 0\# pipe's trajectory and design axis

0\# pipe's trajectory was resurveyed while 5\# pipe was finished. The analysis shows that the $5 \#$ pipe has little effect on $0 \#$ test pipe. After the $5 \#$ pipe was finished, the maximum deviation of the $0 \#$ test pipe is $12 \mathrm{~mm}$, and the average deviation is $4 \mathrm{~mm}$, as shown in Fig .14. 


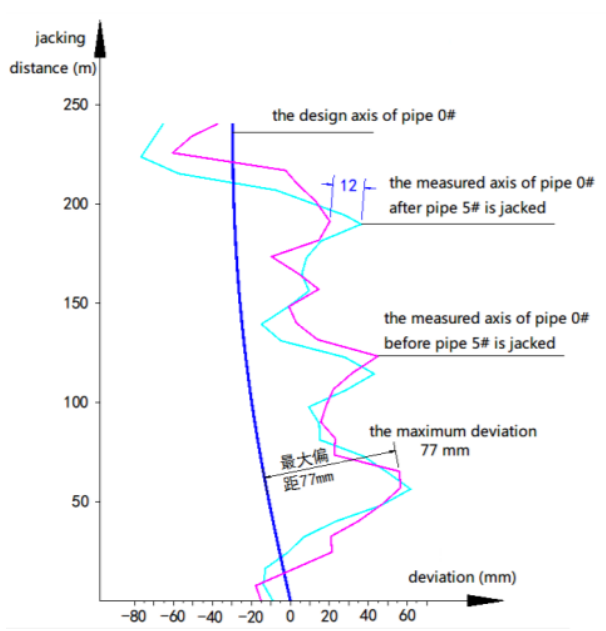

Figure 14. The influence of $5 \#$ pipe on $0 \#$ test pipe

\section{CONCLUSION}

The paper had a preliminary study on the interaction of pipes of the pipe-jacking roof, with the means of model test, numerical simulation and field in-situ test. The conclusions are as follows:

(1) In the process of pipe jacking, the surface in front of the pipe jacking machine cutter uplift and the lateral strain of soil increase. While both sides soil strain decreased or changed less. The soil longitudinal strain increased near front of the pipe jacking machine cutter, soil strain of the area away from that changes less.

(2) According to the results of soil box test numerical simulation, while the prior pipe was finished, the soil settled and the maximum subsidence happened above the pipe jacking, the value reached $2.196 \mathrm{~mm}$. The posterior pipe led to further subsidence of soil, the soil's maximum settlement reached $2.659 \mathrm{~mm}$, which reflecting the disturbance of soil cumulative effect. Settling tank curve roughly symmetrically distributed about the model.

(3) According to the numerical simulation, while the prior pipe finished, the contact pressure distribution on the prior pipe is relatively uniform, which is about $4 \mathrm{kPa}$; the posterior pipe makes the pressure of the prior pipe increased to $6.35 \mathrm{kPa}$.

(4) The soil displacement and strain change rules of the model test are relatively consistent with the numerical simulation results, the results of numerical simulation has very high reference significance.

(5) Through the analysis of the monitoring data of the field tests, on the condition of the pipe jacking construction parameter effectively controlled, properly construction measures, through measuring deviation in time, the accuracy of pipe jacking can meet the engineering requirements, the mutual influence between the pipe jacking roof pipes can be effectively reduces and controlled, which can ensure the nest of pipes forming pipe jacking roof.

\section{REFERENCES}

[1] C. Philip J., G. David, and C. Abbott. "Microtunneling Techniques to Form an in-situ Barrier around existing structures,”. High Level Radioactive Waste Management-Proceedings of the annual international conference, Las Vegas, NV, USA, pp. 386-394.

[2] X. Guyi. "Plan and design of North Fuxing Road Tunnel underpassing Songshan Airport in Taipei,”. Journal of Fuzhou University (Natural Science Edition), vol.25(S1),1997, pp. 56-60.

[3] G. Jinke. "Research on construction scheme of pipe roof tunnel in saturated soft soil,”. Shanghai Highway, vol.1, 2004, pp. 38-43.

[4] L. Xiangyang, Y. Zhiguo, Z. Hehua, C. Yongchang, and L. Xuezeng. "Excavation numerical simulation of culvert box advanced in pipe-roof in saturated soft soil layer,". Underground Space, vol. 24(5), 2004, pp. 688-691. doi: 10.3969/j.issn.16730836.2004.z1.027.

[5] L. Ming, Z. Zuxi, and C. Hong. "Discussion of waterproofing design in box culvert jacking plus pipe curtain method,". China Building Waterproofing, vol. 9, 2006, pp. 39-42. doi 10.3969/j.issn.1007-497X.2006.09.010.

[6] S. Jun, Y. Xingfu, S. Min, and L. Xiangyang "Analysis and prediction on soft ground deformation of a super-large shallow buried 'pipe-roofing and box-culvert' jacking project under construction,". Rock and Soil Mechanics, vol. 27(7),2006, pp. 1021-1027. doi: 10.3969/j.issn.1000-7598.2006.07.001.

[7] C. Sagaseta. "Analysis of undrained soil deformation due to ground loss,". Geotechnique, vol. 37(3) ,1987, pp. 301-320.

[8] N. Loganathan, and H. Poulos. "Analytical prediction for tunneling-induced ground movements in clays," Journal of Geotechnical and Geoenvironmental Engineering, vol. 124(9), 1998, pp.846-856.

[9] G. Wei. "Theoretical study on behaviors of soil and structure during pipe jacking construction,", Zhejiang University, 2005.

[10] F. Li., S. Shen., and C. Luo. Prediction approach of ground deformation induced by pipe jacking construction considering grouting pressure. Rock and Soil Mechanics, vol. 33(1), 2012, pp. 204-208. doi: 10.3969/j.issn.1000-7598.2012.01.032 